\title{
A STUDY BETWEEN EMOTIONAL INTELLIGENCE ALONG WITH HEALTH SCIENCE STUDENTS
}

\author{
Pramila Pudasaini \\ Research scholar, ITM University Gwalior, MP, India. \\ Vandana Bharti \\ Associate Professor, ITM University Gwalior, MP, India.
}

Biju Kumar Thapalia,

Professor, Faculty of Management, Purbanchal University, Biratnagar, Nepal.

\begin{abstract}
Emotional Intelligence (EI) is the ability to identify, assess, and control the emotion of oneself of others and of groups. Emotional Intelligence is the ability to perceive emotions, to access and generate emotions so as to assist thought to understand emotions and emotional knowledge and to reflectively regulate emotions so as to promote emotional and intellectual growth, J Mayer and P. Salovery [18]. Emotional Intelligence (EI) refers specifically to the interplay between intelligence and emotion, an interaction between intelligence and emotion forms the basis for human competence in an activity. At Present Emotional Intelligence attracts interest worldwide in the field of various educational, health and occupational outcomes. Emotional Intelligence is derived from extensive research and theory of thought, feeling and abilities. (pubmed I result(17), n.d.).Students with higher emotional intelligence intelligence felt healthier and happiness, on the other hand result suggested that happiness shows high extroverted students than introverted students. (Ghahramani, Jahromi, Khoshsoroor, Seifooripour\&Sepehrpoor, 2019).
\end{abstract}

Key words: Emotional Intelligence, Health Science students, Emotional Self awareness

Cite this Article: Pramila Pudasaini, Vandana Bharti and Biju Kumar Thapalia, A Study between Emotional Intelligence Along With Health Science Students, International Journal of Management, 11(12), 2020, pp. 2034-2038.

http://iaeme.com/Home/issue/IJM?Volume=11\&Issue=12 


\section{INTRODUCTION}

Emotional Intelligence (EI) is the ability to identify, assess, and control the emotion of oneself of others and of groups. Emotional Intelligence is the ability to perceive emotions, to access and generate emotions so as to assist thought to understand emotions and emotional knowledge and to reflectively regulate emotions so as to promote emotional and intellectual growth, $\mathrm{J}$ Mayer and P. Salovery [18]. Emotional Intelligence (EI) refers specifically to the interplay between intelligence and emotion, an interaction between intelligence and emotion forms the basis for human competence in an activity. At Present Emotional Intelligence attracts interest worldwide in the field of various educational, health and occupational outcomes. Emotional Intelligence is derived from extensive research and theory of thought, feeling and abilities. (pubmed I result(17), n.d.).Students with higher emotional intelligence intelligence felt healthier and happiness, on the other hand result suggested that happiness shows high extroverted students than introverted students. (Ghahramani, Jahromi, Khoshsoroor, Seifooripour\&Sepehrpoor, 2019).

\section{LITERATURE REVIEW}

According to Austin (2004), the concept of EI provides a psychometric framework for the idea that EI relate to life outcomes such as career and relationships success. The theoretical preposition is that individuals who are high in EI are more successful in work-related and nonwork related aspects of life than those who possess low level of EI. It represents growth in evolution of views about the relation between passion and reason, and represents an outgrowth of new theories of intelligence (Grewal \& Salovey, 2005). Mayer-Salovery-Caruso Emotional Intelligence Test, 139 the Bar-On model of emotional-social intelligence, 151 or specially designed 360-degree evaluations57, 97)? Which components of EI are most critical at specific times during the career trajectories of physicians? How should EI be integrated into the constantly increasing burden of skills and knowledge that competent physicians should have? Should all physicians receive leadership development training, or only those who are specifically recruited/ interested Nursing students are required to manage numerous clinical situations, adapt to the different teaching styles and expectations of instructors, work independently toward objectives, and manage conflicts. In addition, some aspects of academic work may be considered highly stressful, such as taking exams and practicing nursing procedures in health care settings. These situations require high levels of emotional management $(15,16 \& 17)$.Emotions have two types of effects on personality. It directly affects the individuals mental functioning, physical functioning and his attitude while indirect effect comes from reactions of members of the social group towards the person who is experiencing the emotions.1 Each person differs to monitor one's own and others emotions, to differentiate among them. Application of this information as perceived by individual helps one's thinking and actions that explains emotional intelligence (EI).2In spite of the technological advances in the last 30 years, today's college students must still contend with aspects that technology cannot address: emotional self-awareness, interpersonal skills, adaptability, impulse control, and many other uniquely human challenges. Even academically competent students may be in jeopardy when entering college if certain aspects of emotional competence are lacking. Recent studies (Crossman, 2007; LaCivita, 2003; Parker et al., 2005; Schutte \&Malouff, 2002) suggest that students are under an increasing level of stress and their ability to manage that stress, adapt to a rapidly changing and dynamic environment while managing to keep impulse control in check are all factors that may jeopardize a first year student's successful transition to the second year of college. Higher education institutions in South Africa are increasingly being driven by the challenges ofsupply and demand. Hence, these institutions are continuously expected to seek strategic innovations aimed at differentiating their core products and services (van Lill, 2010). 
The university at which the current research was undertaken, has recently embarked on a strategic initiative to determine best practice with respect to Teaching and Learning, and is developing graduate attributes aimed to address some of the needs of industry and society at large. Esmaeilli [5] in their study concluded that there is significant relationship between components of emotional intelligence and mental health of men and women totally. A study was conducted by Kaneez [9] about the gender differences on emotional intelligence. The study depicts difference between the genders on the parameters of emotional intelligence, i.e., awareness about self, their ability to manage emotions, ability to motivate self, responsiveness and social skills. It was found that men show more assertiveness, self-recognition and depict more independence and management according to the situations than the women.

\section{STATEMENT OF THE PROBLEM}

To study the emotional intelligence and its five dimensions which are self-awareness, Managing Emotions, Motivating oneself, Empathy and Social Skills among Health Science Students.

\section{RATIONALE OF THE STUDY}

Emotional intelligence is closely linked with high academic success, so it is necessary to promote it in health science students to manage their own emotions and emotions of others, to take care of others and know how to perform with their competencies. As Nursing profession is very sensitive and delicate, there is need to identify the EI levels and its dimensions. In my view, it is necessary to provide information regarding emotional intelligence to health science students to enhance their knowledge and competencies.

\section{RESEARCH METHODOLOGY}

The population of the study consists of Health Science students of PBBN and BSN in college in Chitwan, Shree Medical College. The samples were as per convenience sampling.

\subsection{Research and Sample Design}

The study is descriptive in nature. Sample Unit is nursing students from college. The sample size is 54 .

\subsection{Data Collection and Method}

Primary data is collected by administering questionnaire to respondents and secondary data is collected from published research papers.

\section{ANALYSIS AND INTERPRETATION}

Table 1 Demographic variables of the respondent

\begin{tabular}{|l|l|l|}
\hline Variables & & Total (N=54) \\
\hline & & \\
\hline Age in years & between 20-30 years & $54(100)$ \\
\hline & More than 30 years & 0 \\
\hline Sex & Male & 0 \\
\hline & Female & $54(100)$ \\
\hline Program & PBBN Nursing & $27(50)$ \\
\hline & BSN & $27(50)$ \\
\hline
\end{tabular}


From the above table no 1 among 54 students, the age between 20-30 years is 54 . All the students are female. Moreover, the program from PBBN and BSN are taken. Out of which half number i.e 27 is from PBBN and 27 from BSN.

Table 2.Showing Descriptive Statistics

\begin{tabular}{|l|c|r|r|r|r|r|r|}
\hline \multicolumn{2}{|c|}{ Statistics } & \multicolumn{7}{|c|}{} \\
\hline \multirow{3}{*}{$\mathbf{N}$} & SA & ME & MO & E & \multicolumn{1}{c|}{ SS } & EI \\
\cline { 2 - 8 } & Valid & 54 & 54 & 53 & 54 & 54 & 53 \\
\cline { 2 - 8 } Mean & 0 & 0 & 1 & 1 & 1 & 1 \\
\hline Median & 3.79 & 3.79 & 3.64 & 3.48 & 3.69 & 3.62 \\
\hline Std. Deviation & 1.119 & 1.119 & 1.142 & 1.190 & 1.141 & 1.147 \\
\hline Skewness & -0.816 & -0.816 & -0.496 & -0.436 & -0.425 & -0.493 \\
\hline Std. Error of Skewness & 0.325 & 0.325 & 0.326 & 0.326 & 0.326 & 0.326 \\
\hline Kurtosis & 0.281 & 0.281 & -0.265 & -0.323 & -0.723 & -0.299 \\
\hline Std. Error of Kurtosis & 0.640 & 0.640 & 0.642 & 0.642 & 0.642 & 0.642 \\
\hline Minimum & 1 & 1 & 1 & 1 & 1 & 1 \\
\hline Maximum & 5 & 5 & 5 & 5 & 5 & 5 \\
\hline
\end{tabular}

From the above table no 2 of descriptive statistics, it is concluded that the average for the factor Self-awareness is moderate positive with the value of 3.7518, because of their attention of social circumstance and capacity to control feelings in themselves and in others, thus can expand work fulfillment. The average for the factor managing emotions has moderate positive relation with the value 3.3204, which has ability to stay focused and think clearly even when experiencing powerful emotions. Being able to manage your own emotional state is essential for taking responsibility for your actions, and can save you from hasty decisions that you later regret. The average for the factor Motivating on self has moderate positive value 3.5499 which has the ability to use your deepest emotions to move and guide you towards your goals. This ability enables you to take the initiative and to preserve in the face of obstacles and setbacks. The average of the factor for Empathy has moderate positive value of 3.6138, the ability to sense, understand and respond to what other people are feeling. Self-awareness is essential to having empathy with others. The average of the factor has moderate positive value for Social skill is 3.7324 hence the ability to manage, influence and inspires emotions in others. Being able to handle emotions in relationships and being able to influence and inspire others are essential foundation skills for successful teamwork and leadership. The Standard deviation is ranging from 0.5 in all the dimension. The median is 3.5 for all the variables.

\section{SUGGESTION}

Every parent responsibility is to teach their child to be emotionally literate, which helps to develop their inter and intrapersonal relationships. The students need to develop EI and its dimensions, in order to overcome anxiety, stress, frustration, anger, hurt, disappointment and despair. This would help the students cope in difficult situations in life and help them to improve their self-esteem, courage, self-reliance and self-regulations and also enable them to handle life on their own way. 


\section{CONCLUSION}

The students have higher level of Emotional Intelligence, understanding managing and Empathy. So in order to increase the level of Emotional Intelligence schools and colleges has to conduct training and awareness programs. Students can get trained by specialists and counselors who are trained in Emotional Intelligence. These experts can help students to know how they can improve their performance by applying Emotional Intelligence. If students understand, control and use their emotions effectively, they will significantly improve academic performance and there by create positive working environment in future.

\section{ACKNOWLEDGMENT}

The authors appreciate all those who participated in the study and helped to facilitate the research process

\section{REFERENCES}

[1] Austin, E. J. (2004). An investigation of the relationship between trait emotional intelligence performance tasks. Journal of Personality and individual differences, 36,1855-1864

[2] Bean, J. (2003). Why students leave college. ASHE-ERIC Higher Education Report 30(2) p.4373.

[3] Beauvais, A.M, Brady, N., O'Shea, E.R. \& Griffin, M.T. (2011). Emotional intelligence and nursing performance among nursing students. Nurse Education Today, 31(4), 396-401.

[4] Cooper RK, Sawaf A. Executive EQ. Emotional intelligence in leadership and organizations, New York. GrossetPutnum. 1997.

[5] Crossman, J. (2007). The role of relationships and emotions in students' perceptions of learning and assessment. Higher Education Research \& Development, 26(3), 313327.

[6] Ergur, D.O. (2009). How can education professionals become emotionally intelligent? ProcediaSocial and Behavioral Sciences, 1(1), 1023-1028.

[7] Esmaeilli, N. \&Jamkhanch, E.B. (2013), The relationship between emotional intelligence and mental health in Humanism college students At IAU'

[8] Kaneez, U. 2006. "Emotional Intelligence among the Individual with Depression and without Depression: A Comparative Study", Unpublished M.Sc. Dissertation. Nat. Instt. Psychol., Quaid-e-Azam Univ., Islamabad.

[9] LaCivita, L. K. (2003). An examination of emotional intelligence factors: Their relationship to academic achievement and the implications for retention of the atrisk community college student (Doctoral dissertation, Capella University). Retrieved from http://www.proquest.com/enUS/products/dissertations/individuals.shtml

[10] Larin, H.M., Benson, G., Martin, L., Wessel, J., Williams, R. \& Ploeg, J. (2011). Examining change in emotional social intelligence, caring, and leadership in health professions students. Journal of Allied Health, 40(2), 96-102

[11] Parker, J. D., Duffy, J. M., Wood, L. M., Bond, B. J., \& Hogan, M. J. (2005). Academic achievement and emotional intelligence: Predicting the successful transition from

[12] Salovey P, Mayer JD. Emotional intelligence. Imagination Cogn Pers. 1989; 9(3):185-211. 